\title{
OPTOELECTRONIC PROPERTIES OF TRIPHENYLAMINE BASED DYES FOR SOLAR CELL APPLICATIONS. A DFT STUDY
}

\author{
Zakaria Mohyi Eddine Fahim ${ }^{\mathrm{a}}$, Si Mohamed Bouzzine ${ }^{\mathrm{a}, \mathrm{b}}$, Mouay Mustapha Hamidic, Mohammed Bouachrine ${ }^{\mathrm{d}}$, Mohamed \\ Hamidi $^{a}$, Guillermo Salgado-Morán ${ }^{\mathrm{e}}$, Luis H. Mendoza-Huizar ${ }^{\mathrm{f}, *}$, and Giaan A. Alvarez-Romero ${ }^{\mathrm{f}}$ \\ ${ }^{a} E q u i p e$ d'Electrochimie et Environnement, Faculté des Sciences et Techniques, Université Moulay Ismaiil, B.P. 509 Boutalamine, \\ Errachidia, Morocco \\ ${ }^{\mathrm{b}}$ Centre Régional des Métiers d'Education et de Formation, BP 8; Errachida, Morocco \\ 'Equipe des Matériaux Inorganiques, Département de Chimie, Faculté des Sciences et Techniques, Université Moulay Ismaïl, B.P. \\ 509 Boutalamine, Errachidia, Morocco \\ ${ }^{\circledR}$ Ecole Supérieure de Technologie de Meknès, University Moulay Ismail, Meknès, Morocco \\ eDepartamento de Ciencias Químicas, Facultad de Ciencias Exactas, Universidad Andrés Bello, Sede Concepción, Autopista \\ Concepción-Talcahuano 7100, Talcahuano, Chile \\ fUniversidad Autónoma del Estado de Hidalgo, Academic Area of Chemistry, Carretera Pachuca-Tulancingo Km. 4.5 Mineral de \\ la Reforma, Hgo, México
}

Recebido em 03/06/2017; aceito em 07/11/2017; publicado na web em 11/12/2017

\begin{abstract}
Dye-sensitized solar cells (DSSCs) based on triphenylamine (TPA) as a donor group linked with the acceptor cyanoacrylic acid electron acceptor by $2,2^{\prime}$-bithiophene as $\pi$-bridged (D- $\pi$-A) has been investigated by Density Functional Theory (DFT) at the B3LYP/6-311G(d,p) level of theory, to establish the conformational orientation of cyanoacrylic acid group as well as evaluate the effect of planarizing the 2,2'-bithiophene unit in position 3 and 3' by electron withdrawing or donor groups on the electronic structure properties of ground and doping(n,p) states. Also, the Time Dependent Density Functional Theory (TD-DFT) at the CPCM-TD-CAM-B3LYP//CAM-B3LYP/6-311G(d,p) level of theory were selected to modulate the electronic absorption spectra and charge-transfer capabilities of the molecules analyzed in the present work. The results indicate that adding an auxiliary donor or withdrawing group to the 2,2'-bithiophene in the (D- $\pi$-A) arrangement allow to modify the LUMO's energy of the dyes, while the HOMO's energy is slightly affected.
\end{abstract}

Keywords: solar cell; dyes; triphenylamine; TD-DFT; UV-Vis.

\section{INTRODUCTION}

Recently, the search for sustainable, reliable and clean energy has become one of the main challenges in different fields such as chemistry, physics and material sciences. Thus, it is not so strange that many researchers have focused their efforts in the development and optimization of new renewable energy technologies. In this sense, the Grätzel cell, also called organic dye-sensitized solar cell (DSSC) represents a good alternative to produce clean and renewable energy at low cost in comparison to the inorganic semiconductor-based photovoltaic devices employed for the conversion of sunlight into electricity. ${ }^{1}$ A typical DSSC works based on the recombination between electron and "holes" on the surface of semiconductor oxide (usually $\mathrm{TiO}_{2}$ ), that adsorbs the dye molecules (sensitizers). These sensitizers absorb the sunlight and then the photoexcited electrons from the dyes can be rapidly injected into the conduction band of the semiconductor photoanode,$^{2}$ while the oxidized organic dye is then reduced by a redox electrolyte (usually the $\mathrm{I}^{-} / \mathrm{I}_{3}{ }^{-}$couple). ${ }^{3}$ Significant advances have been reached in the molecular design of these kind of organic dyes, ${ }^{4-6}$ getting efficiencies close to $13 \%$, when dyes based on porphyrin are used. ${ }^{7}$ This organic molecular design DSSC have a donor part (D) linking with a terminal acceptor (A) by a $\pi$-bridged block (D- $\pi$-A). In this context, several organic dyes based in coumarin,${ }^{8}$ indoline,${ }^{9}$ carbazole,${ }^{10}$ and triphenylamine derivatives (TPA) ${ }^{11}$ as the donor part, and containing a terminal cyanoacrylic

*e-mail: hhuizar@uaeh.edu.mx acid (CA), as electron accepting moiety, have been proposed as promising candidates for get high power conversion efficiency.

In this sense, TPA show excellent solubility, good stability, and high photoluminescent efficiency, by which have been extensively used in the fabrication of optoelectronic and electronic devices, ${ }^{12}$ such as organic light emitting diodes (OLEDs), ${ }^{13-15}$ dye-sensitized solar cells, ${ }^{16}$ field-effect transistors, ${ }^{17}$ among others. Here, it is important to mention that TPA are able to expand the light absorption ability of the dye. ${ }^{18-23}$ Additionally, their non-planar structure avoid the aggregation of the dye on the $\mathrm{TiO}_{2}$ surface. ${ }^{24}$ Consequently, TPA are considered as ideal donor units in organic dyes, because are able to exhibit a good electron donating and high hole-transporting capability..$^{24,25}$ New dyes based on TPA as electron donor group have been studied from experimental, ${ }^{26-30}$ and theoretical, ${ }^{16,27,31-34}$ point of views. Hence, a lot of effort has been dedicated to understand the relationship between the molecular structure of these dyes based on TPA, CA and different $\pi$-spacers, in order to analyze their charge-transporting properties. ${ }^{35-37}$ The effect of different $\pi$-spacers on the performance of dye-sensitized Solar Cells Based on TPA-CA has been reported in the literature. For example, different substituents such as phenylene units, $2,2^{\prime} ; 5^{\prime}, 2^{\prime \prime}$-terthiophene (TT), dithieno[3,2-b;2',3'-d]thiophene (DTT), ${ }^{38} \mathrm{OMe}, \mathrm{OEt}, \mathrm{OHe}$, and $\mathrm{OH},{ }^{39}$ thiophene, ${ }^{40}$ thiadiazole derivatives, ${ }^{41}$ have been employed. Specifically, triphenylamine dyes containing a variable number of thiophene units as $\pi$-spacers have shown that, if the length of the conjugate bridge is increased, there is a better match between the absorption properties of dyes and solar spectrum. ${ }^{42}$ Recently, it was reported that bithiophene substituted with benzimidazole allow to get a T-shaped arrangement of dye, which 
improves the efficiency of the charge transfer process..$^{43}$ Additionally, it has been reported that if benzimidazole is decorated with different functional groups (such as $-\mathrm{OCH}_{3},-\mathrm{N}\left(\mathrm{CH}_{3}\right)_{2},-\mathrm{CF}_{3}$ ), the resulting dye is a donor-acceptor type molecular scaffold. ${ }^{44}$ Based on the above mentioned, in this paper, we propose the theoretical design of a set of new organic sensitizers based on triphenylamine (TPA), linked with the acceptor cyanoacrylic through 2,2'-bithiophene as $\pi$-bridged. The molecular design D1 (TPA-CA linked by 2,2'-bithiophene), was investigated theoretically to find the adequate conformation of the cyanoacrylic acid moiety and to assess the role of planarized 2,2'-bithiophene unit in position 3 and 3' substituted with electron withdrawing groups $\left(\mathrm{C}=\mathrm{O}(\mathrm{D} 2), \mathrm{C}=\mathrm{S}(\mathrm{D} 3)\right.$ and $\left.\mathrm{C}=\mathrm{C}(\mathrm{CN})_{2}(\mathrm{D} 4)\right)$, or electron donor groups $\left(\mathrm{C}\left(\mathrm{CH}_{3}\right)_{2}(\mathrm{D} 5)\right.$ and $\left.\mathrm{C}=\mathrm{C}\left(\mathrm{CH}_{3}\right)_{2}(\mathrm{D} 6)\right)$. Thus, we analyzed the geometries, electronic and absorption spectra properties of the dyes designed, see Figure 1.

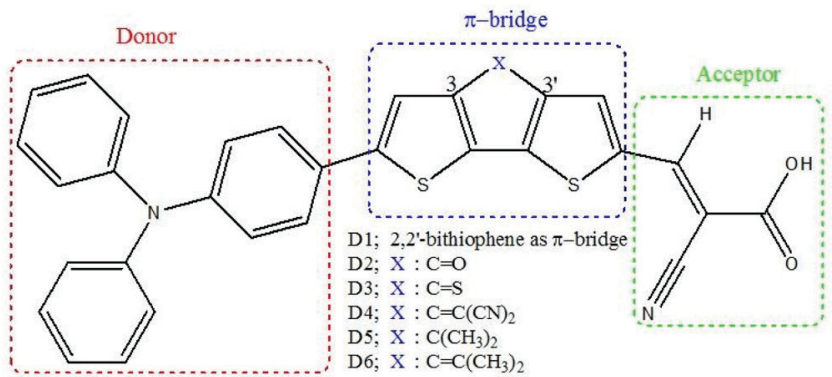

Figure 1. General molecular structure of the dyes analyzed in the present work

\section{METHODOLOGY}

The optimal conformations of the ground and doped states structures were subject to full geometry optimization in ethanol solvent employing the hybrid functional B3LYP, ${ }^{45-47}$ with the 6-311G(d,p) basis set, ${ }^{48}$ and the conductor-like polarizable continuum model (CPCM) solvation model. ${ }^{49} \mathrm{~A}$ subsequent frequency calculation was performed on the optimized structures and no imaginary frequencies were obtained. The electronic absorption spectra and charge-transfer capabilities of studied dyes were evaluated using the Time Dependent Density Functional Theory (TD-DFT) ${ }^{50}$ at the CPCM-TD-CAM-B3LYP//CAM-B3LYP/6-311G(d,p) level of theory. ${ }^{49-54}$ All TD-DFT simulations were performed as singlet and employing 6 excited states. In all calculations, the default convergence criterion was employed. All calculations were performed with the Gaussian 09 packages, ${ }^{55}$ and were visualized with Gaussview (5.0.9 release, Gaussian Inc., Wallingford, CT, USA). ${ }^{56}$

\section{RESULTS AND DISCUSSION}

\section{Structural parameters}

An important step to achieve new accurate absorption spectra results is predicting reliable molecular geometries of the designed dyes, in the ground state. In this regard, an initial conformational analysis on the dye D1 (see Figure 2) of the cyanoacrylic acid moiety, was performed at the CPCM-B3LYP/6-311G(d,p) level of theory. The rotating around torsion dihedral angle between the cyanoacrylic acid moiety and adjacent thiophene ring at $0^{\circ}$ and $180^{\circ}$ shows that the minima E-180 was a global minimum structure of D1, which is stable only by $0.39 \mathrm{kcal}^{\mathrm{mol}}{ }^{-1}$ in comparison to the E- 0 configuration. The last one is probably due to weak Van-deer-Waals interaction present between the sulfur atom of thiophene ring and the nitrogen atom of cyanoacrylic acid moiety. This small energy barrier confirms the coexistence of these two conformers, see Figure 1S in supplementary material. Thus, the optimized geometries of all derivate dyes were calculated at the CPCM-B3LYP/6-311G(d,p) level of theory using the E-180 configuration in neutral forms and they are showed in Figure 2.

In order to examine the bonds of the dye that participate in the intramolecular charge transfer from TPA to the terminal acceptor cyanoacrylic acid, we analyze a set of selected conjugated bond lengths $\left(d_{\mathrm{x}}\right.$, where $\left.\mathrm{x}=1-10\right)$ and dihedral angles $(\theta)$ in the molecular structures, see Figure $2 \mathrm{~S}$, in supplementary material. These bonds are located between the rings in $\pi$-bridge blocks for neutral, positive and negative doped(n,p) states, and their values were calculated at the CPCM-B3LYP/6-311G(d,p) level of theory and are reported as supplementary material in Table $1 \mathrm{~S}$.

From the data reported in Table $1 \mathrm{~S}$, it is possible to note that the selected bond lengths show an alteration between simple and double bond length in the skeleton linking the donor TPA and the acceptor cyanoacrylic acid group. Furthermore, except for D3 and $\mathrm{D} 4$, in the doped(n,p) forms, the selected single bonds of the neutral forms are shortened $\left(\Delta^{+}\right.$and $\Delta^{-}$were positive), while the double bonds lengthens $\left(\Delta^{+}\right.$and $\Delta^{-}$were negative), resulted in an enhancement of the quinoïdal character in the $\pi$-conjugated part from the donor TPA and the acceptor cyanoacrylic acid group. This quinoïdal character of $\pi$-bridge moiety was also enhanced by reducing the dihedral angle values $\left(\theta_{1} \sim 25^{\circ}\right)$ between the TPA, and the thiophene ring of $\pi$-bridge moiety of all studied dyes upon doped indicate more easier delocalization of $\pi$-electrons with high planarity order of the $\pi$-bridge block.

\section{Electronic parameters and absorption spectra}

Figure 3 shows the energy values and isodensity plots of the Highest Occupied Molecular Orbital (HOMO) and the Lowest Unoccupied Molecular Orbital (LUMO) deduced in ethanol solvent using the CPCM model at the B3LYP/6-311G(d,p) level of theory. Interestingly, when strong electron withdrawing groups are used in the bridging, is clear that the HOMO-LUMO gap is lower in comparison when donor groups are employed. Also, note that all LUMO's energy values of the dyes are less negative than $\mathrm{E}_{\mathrm{CB}}\left(\mathrm{TiO}_{2}\right),{ }^{57}$ with sufficiently large driving force for effective electron injection. ${ }^{2}$ Observe that, in comparison to D1, the presence of electron withdrawing groups in the bridging low slightly the value of the HOMO following the order D1 $>$ D2 $>$ D3 $>$ D4, while electron donor groups in the bridging slightly elevate the energy of this orbital. Note that these energy values are more negative than $\mathrm{I}^{-} / \mathrm{I}_{3}{ }^{-}$redox potential, indicating that the oxidized dyes could be efficiently regenerated from the reduced species in the electrolyte to give an efficient charge separation. ${ }^{3}$ Considering these results, the gap values showed that D1 was decreased when we introduce electron withdrawing groups, which make transitions from HOMO to LUMO levels easier upon excitation.

The UV-Vis spectra for compounds D1-D6 in ethanol solvent were calculated at the CPCM-TD-CAM-B3LYP/6-311G(d,p) level of theory and are depicted in Figure 4. Note that the position of the absorption bands is influenced by the substituent in the 2,2'-bithiophene. Also, it is possible to note that the compound D2 shows the larger bathochromic shift of the absorption peak in UV-vis spectra, followed by D6 and D5. Last result suggests that D2 is the larger conjugated system of this set of dyes. In all cases, the excitation presents an intense band in the UV-Vis region (see Figure 4) with a high oscillator strength (Table 2S, in supplementary material), which can be assigned to an intramolecular charge transfer (ICT) from an electron rich side to an electron poor zone. Also, observe that in most of cases, the major absorption band comes from $\mathrm{HOMO} \rightarrow$ LUMO transition from triphenylamine and bithiophene, in centre, to partly of bithiophene in the center and cyanoacrylic acid, 
D1

D2
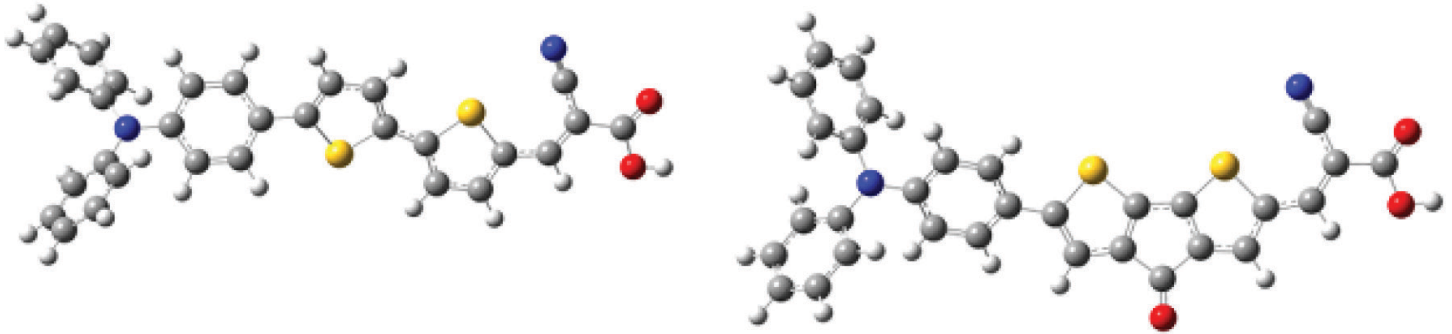

D3

D4

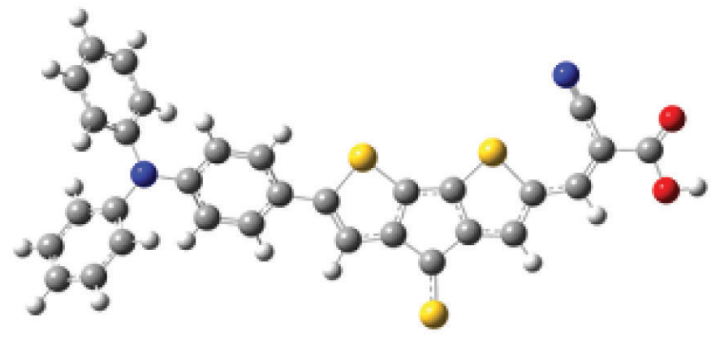

D5



D6


Figure 2. Optimized structures of all studied dyes at the CPCM-B3LYP/6-311G(d,p) level of theory



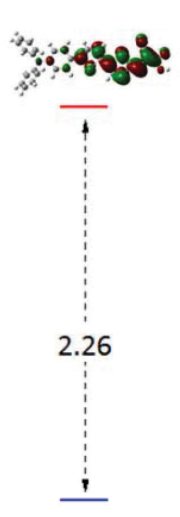

Sologio::

D1

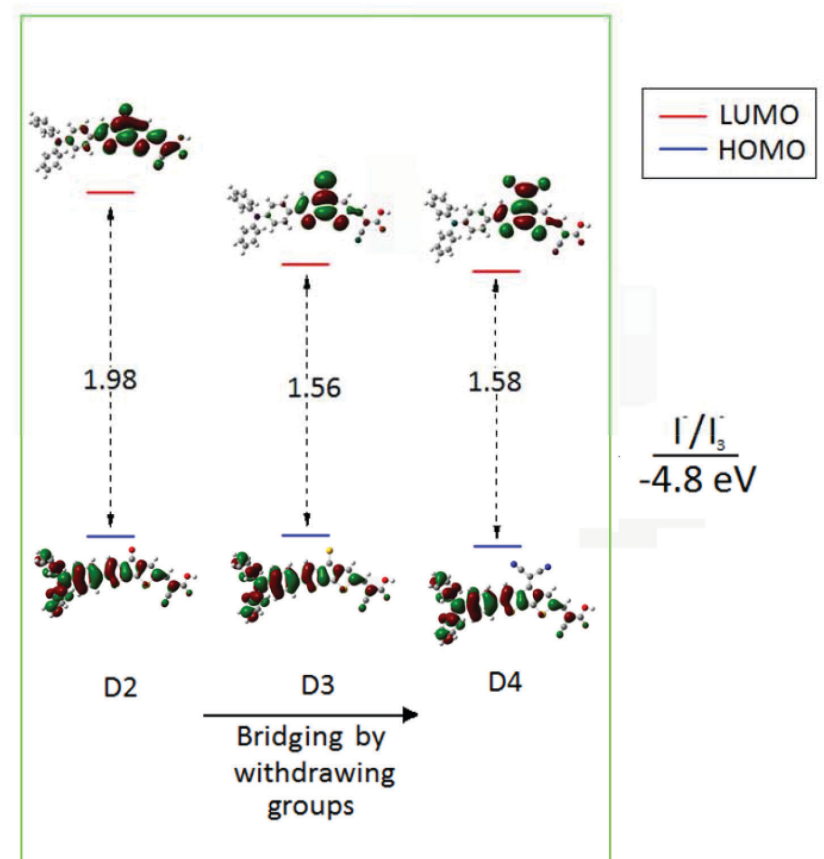

Figure 3. The HOMO and LUMO energies levels (eV) of all studied dyes calculated in ethanol solvent obtained by CPCM-B3LYP/6-311G(d,p) 
see the electronic density plots in Figure 3. On the other hand, it is clear that this band consists, at least, of an additional electronic transition, ie, HOMO- $1 \rightarrow$ LUMO, see Table $2 \mathrm{~S}$, which is related to an ICT from triphenylamine- bithiophene to bithiophene-cyanoacrylic acid. Additionally, it is interesting to note that the oscillator strength values of D2, D3 and D4 are lower than the obtained for D1, D5 and D6. Here, it is convenient to remind that the oscillator strength expresses the strength of transitions to the excited states. Thus, a higher the oscillator strength indicates a higher possibility for the molecule to be sensitized..$^{58-62}$

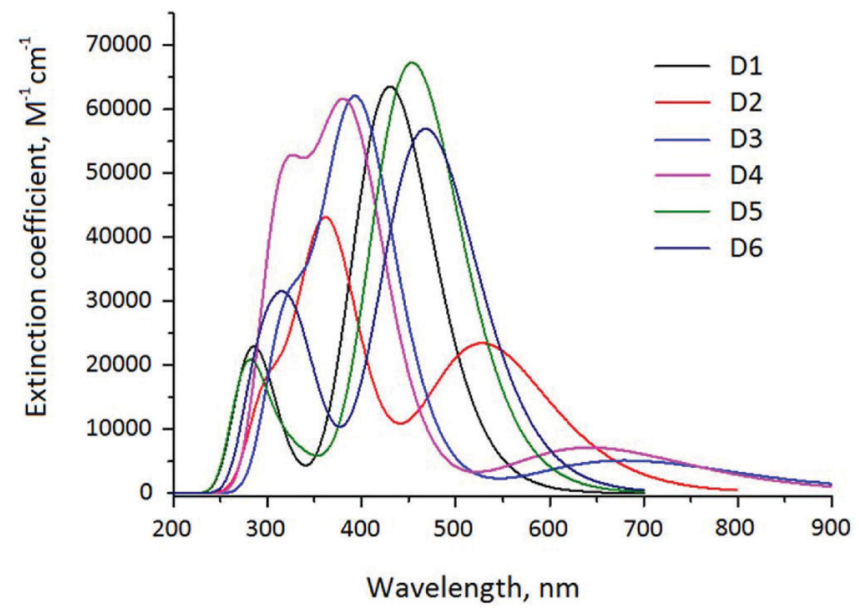

Figure 4. UV-Vis spectrum of studied dyes in ethanol solvent obtained by CPCM-TD-CAM-B3LYP/6-311G $(d, p)$ level

\section{CONCLUSIONS}

In this paper, we have designed novel D- $\pi$-A containing triphenylamine as a donor group linked with the acceptor cyanoacrylic acid electron acceptor by 2,2 '-bithiophene as $\pi$-bridge. The small energy barrier founded between two conformers E-0 and E-180 confirms the coexistence of these two conformers. Introducing electron withdrawing groups in $\pi$-bridge was a good strategy to reducing the gap energy by stabilizing the LUMO energy level slightly stabilize the HOMO, result in a red shift of the maximum absorption bands, which causes that the dyes analyzed are able to absorb and convert the UV-Vis and near infrared light to current. Thus, our results indicate that adding an auxiliary donor or withdrawing group to the 2,2'-bithiophene in the D- $\pi$-A structure allow us to modify significantly the LUMO's energy while the HOMO's energy is slightly affected by which this study gave insight into the electronic transition of the isolated dyes designed in the present study.

\section{SUPPLEMENTARY MATERIAL}

Figures $1 \mathrm{~S}$ to $2 \mathrm{~S}$ and Tables $1 \mathrm{~S}$ to $2 \mathrm{~S}$ can be found at http:// quimicanova.sbq.org.br in PDF format, with free access.

\section{ACKNOWLEDGEMENTS}

GSM thanks to the Department of Chemistry at the Universidad Andres Bello, Concepcion, Chile. LHMH gratefully acknowledges financial support from CONACYT (Projects CB2015-257823) and to the Universidad Autónoma del Estado de Hidalgo.

\section{REFERENCES}

1. O’regan, B.; Grätzel, M.; Nature 1991, 353, 737.
2. Subramanian, V.; Electrochem. Soc. Interface 2007, 16, 32.

3. Boschloo, G.; Hagfeldt, A.; Acc. Chem. Res. 2009, 42, 1819.

4. Ito, S.; Nazeeruddin, Md. K.; Liska, P.; Comte, P.; Charvet, R.; Péchy, P.; Jirousek, M.; Kay, A.; Zakeeruddin, S.M.; Grätzel, M. Prog. Photovoltaics 2006, 14, 589.

5. Hagfeldt, A.; Boschloo, G.; Sun, L.; Kloo, L.; Pettersson, H.; Chem. Rev. 2010, 110, 6595

6. Wu, Y.; Zhu, W.; Chem. Soc. Rev. 2013, 42, 2039.

7. Mathew, S.; Yella, A.; Gao, P.; Humphry-Baker, R.; Curchod, B. F.; Ashari-Astani, N.; Tavernelli, I.; Rothlisberger, U.; Khaja Nazeeruddin, Md.; Grätzel, M.; Nat. Chem. 2014, 6, 242.

8. Wong, B. M.; Codaro, J. G.; J. Chem. Phys. 2008, 129, 214703.

9. Horiuchi, T.; Miura, H.; Sumioka, K.; Uchid, S.; J. Am. Chem. Soc. 2004, 126, 12218.

10. Sathiyan, G.; Sivakumar, E. K. T.; Ganesamoorthy, R.; Thangamuthu, R.; Sakthivel, P.; Tetrahedron Lett. 2016, 57, 243.

11. Mahmood, A.; Solar Energy 2016, 123, 127.

12. Hua, J.L.; Li B.; Meng F.S.; Ding F.; Qian S.X.; Tian H; Polymer 2004, $45,7143 \mathrm{e} 9$

13. Huang, J. H.; Su J. H.; Li, X.; Lam M. K.; Fung K. M.; Fan H. H.; J. Mater. Chem. 2011, 21, 2957.

14. Xu, L.; Zhao, Y.; Long, G.; Wang, Y.; Zhao, J.; Li, D.; RSC Adv. 2015, $5,63080 \mathrm{e} 6$

15. Zhang, Q.; Ning, Z. J.; Tian, H.; Dyes Pigm. 2009, 81, 80e4.

16. Yang, Z.; Wang, D.; Bai, X.; Shao, C.; Cao, D.; RSC Adv. 2014, 4, $48750 \mathrm{e} 7$.

17. Song, Y.; Di, C.; Xu, W.; Liu, Y.; Zhang, D.; Zhu, D.; J. Mater. Chem. 2007, 17, 4483e91.

18. Karthikeyan, C.; Peter, K.; Wietasch, H.; Thelakkat, M.; Sol. Energy Mater. Sol. Cells 2007, 91, 432.

19. Yang, Z.; Wang, D.; Bai, X.; Shao, C.; Cao, D.; RSC Adv. 2014, 4, 48750.

20. Wang, X.; Lv, L.; Gu, W.; Wang, X.; Dong, T.; Yang, Z.; Cao, H.; Huang, H.; Dyes Pigm. 2017, 140, 141e149.

21. Mahmood, A.; Sol. Energy 2016, 123, 127.

22. Ning, Z. J.; Tian, H.; Chem. Commun. 2009, 5483; Yum, J.-H.; Hagberg, D.P.; Moon, S.-J.; Karlsson, K.M.; Marinado, T.; Sun, L.; Hagfeldt, A.; Nazeeruddin, M. K.; Graetzel, M.; Angew. Chem., Int. Ed. 2009, 48, 1576.

23. Zhao, C.; Wang, T.; Li, D.; Lu, T.; Liu, D.; Meng, Q.; Zhang, Q.; Li, F.; Li, W.; Hu, W.; Wang, L.; Zhou, X.; Dyes Pigm. 2017, 256e264

24. Wang, C.; Li, J.; Cai, S.; Ning, Z.; Zhao, D.; Zhang, Q.; Su, J.-H.; Dyes Pigm. 2012, 94, 40

25. Iwan; A.; Sek, D.; Prog. Polym. Sci. 2011, 36, $1277 \mathrm{e} 325$.

26. Zhao, D-X.; Bian, L-Y.; Luo, Y-X.; Zhang, M-D.; Cao, H.; Chen, M-D.; Dyes Pigm. 2017, 140, 278e285.

27. Shang, H.; Li, Q.; Jiang, K.; Zhan, X.; J. Energy Chem. 2016, 25, 615.

28. Lu, F.; Qi, S.; Zhang, J.; Yang, G.; Zhang, B.; Feng, Y.; Dyes Pigm. 2017, 141, 161e168.

29. Tan, H.; Cai, D.; Liu, Z.; Zhong, F.; Lv, H.; Zhang, X.; Yang, S.; Pan, C.; Synth. Met. 2016, 214, 56.

30. Fattori, A.; Majer, R.; Mazzanti, A.; Ottaviani, M. F.; Modelli, A.; Mantellini, F.; Santeusanio, S.; Dyes Pigm. 2017, 145, 246e255.

31. Ramkumar, S.; Manidurai, P.; Spectrochim. Acta, A 2017, 173, 425.

32. Alamy, A. E.; Bourass, M.; Amine, A.; Hamidi, M.; Bouachrine, M.; Karbala International Journal of Modern Science 2017, 3, $75 \mathrm{e} 82$

33. Inostroza, N.; Mendizabal, F.; Arratia-Pérez, R.; Orellana, C.; LinaresFlores, C. J. Mol. Model. 2016, 22, 25.

34. Tarsang, R.; Promarak, V.; Sudyoadsuk, T.; Namuangruk, S.; Jungsuttiwong, S.; J. Photochem. Photobiol., A 2014, 273, 8.

35. Tang, S.; Li, W.; Shen, F.; Liu, D.; Yang, B.; Ma, Y.; J. Mater. Chem. 2012, 22, 4401e8. 
36. Jiang, P.; Zhao, D. D.; Yang, X. L.; Zhu, X. L.; Chang, J.; Zhu, H. J.; Org. Biomol. Chem. 2012, 10, 4704e11.

37. Gudeika, D.; Bundulis, A.; Mihailovs, I.; Volyniuk, D.; Rutkis, M.; Grazulevicius, J. V.; Dyes Pigm. 2017, 140, 431e440.

38. Yang, X.; Chen, R.; Zhang, R.; Hagfeldt, A.; Sun, L.; J. Phys. Chem. C 2008, 112, 11023.

39. Xu, J.; Zhu, L.; Fang, D.; Chen, B.; Liu, L.; Wang, L.; Xu, W.; Chem. Phys. Chem. 2012, 13, 3320.

40. Li, W.; Chen, J.; Bai, F.-Q.; Zhang, H.-X.; Spectrochim. Acta, A 2014, $118,1144$.

41. Fan, W.; Deng, W.-q.; Commun. Comput. Chem., 2013, 1, 152.

42. Xu, J.; Wang, L.; Liang, G.; Bai, Z.; Wang, L.; Xu, W.; Shen, X.; Spectrochim Acta, A 2011 78, 287.

43. Xu, B.; Li, Y.; Song, P.; Ma, F.; Suna, M.; Sci. Rep. 2017, 7, 45688.

44. Saltan, G. M.; Dinçalp, H.; Kırmacı, E.; Kıran, M.; Zafer, C.; Spectrochim. Acta, A 2018, 188, 372.

45. Becke, A. D.; J. Chem. Phys. 1993, 98, 5648.

46. Becke, A. D.; Phys. Rev. A: At., Mol., Opt. Phys. 1988, 38, 3098.

47. Lee, C.; Yang, W.; Parr, R. G.; Phys. Rev. B: Condens. Matter Mater. Phys. 1988, 37, 785 .

48. Krishnan, R. B. J. S.; Binkley, J. S.; Seeger, R.; Pople, J. A.; J. Chem. Phys. 1980, 72, 650.

49. Barone, V.; Cossi, M.; J. Phys. Chem. A 1998, 102, 1995.

50. Furche, F.; Ahlrichs, R.; J. Chem. Phys. 2002, 117, 7433.

51. Cossi, M.; Rega, N.; Scalmani, G.; Barone, V.; J. Comput. Chem. 2003, 24, 669 .

52. Yanai, T.; Tew, D. P.; Handy, N. C.; Chem. Phys. Lett. 2004, 393, 51.

53. Lange, A. W.; Rohrdanz, M. A.; Herbert, J.M.; J. Phys. Chem. B, 2008, 112,6304

54. Rohrdanz, M. A.; Herbert, J. M.; J. Chem. Phys. 2008, 129, 034107.
55. Frisch, M. J.; Trucks, G. W.; Schlegel, H. B.; Scuseria, G. E.; Robb, M. A.; Cheeseman, J. R.; Scalmani, G.; Barone, V.; Mennucci, B.; Petersson, G. A.; Nakatsuji, H.; Caricato, M.; Li, X.; Hratchian, H. P.; Izmaylov, A. F.; Bloino, J.; Zheng, G.; Sonnenberg, J. L.; Hada, M.; Ehara, M.; Toyota, K.; Fukuda, R.; Hasegawa, J.; Ishida, M.; Nakajima, T.; Honda, Y.; Kitao, O.; Nakai, H.; Vreven, T.; Montgomery, J. A., Jr.; Peralta, J. E.; Ogliaro, F.; Bearpark, M.; Heyd, J. J.; Brothers, E.; Kudin, K. N.; Staroverov, V. N.; Kobayashi, R.; Normand, J.; Raghavachari, K.; Rendell, A.; Burant, J. C.; Iyengar, S. S.; Tomasi, J.; Cossi, M.; Rega, N.; Millam, N. J.; Klene, M.; Knox, J. E.; Cross, J. B.; Bakken, V.; Adamo, C.; Jaramillo, J.; Gomperts, R.; Stratmann, R. E.; Yazyev, O.; Austin, A. J.; Cammi, R.; Pomelli, C.; Ochterski, J. W.; Martin, R. L.; Morokuma, K.; Zakrzewski, V. G.; Voth, G. A.; Salvador, P.; Dannenberg, J. J.; Dapprich, S.; Daniels, A. D.; Farkas, Ö.; Foresman, J. B.; Ortiz, J. V.; Cioslowski, J.; Fox, D. J.; Gaussian 09, Revision A.01, Gaussian, Inc., Wallingford CT, 2009.

56. Gaussview Rev. 5.09, Windows version. Gaussian, Inc., Wallingford CT, 2003.

57. Reyes-Coronado, D.; Rodríguez-Gattorno, G.; Espinosa-Pesqueira, M. E.; Cab, C.; de Coss, R.; Oskam, G.; Nanotechnology 2008, 19, 145605.

58. Galappaththi, K.; Ekanayake, P.; Petra, M. I.; Scientia Bruneiana 2016, 15, 153.

59. De Angelis, F.; Fantacci, S.; Selloni, A.; Nazeeruddin, M. K.; Grätzel, M.; J. Am. Chem. Soc. 2007, 129, 14157.

60. Kumara, N. T. R. N.; Kooh, M. R. R.; Lim, A.; Iskandar, M.; Voo, N. Y.; Int. J. Photoenergy 2013, 2013, 1

61. De Angelis, F.; Fantacci, S.; Selloni, A.; Nazeeruddin, M. K.; Grätzel, M., J. Phys. Chem. C 2010, 114, 6054.

62. He, L.-J.; Chen, J.; Bai, F.-Q.; Jia, R.; Wang, J.; Zhang, H.-X.; Dyes Pigm. 2017, 141, 251 